\title{
ON A CASE
}

or

\section{PSEUDO-HYPERTROPHIC MUSCULAR PARALYSIS.}

\author{
BY \\ J. LOCKHART CLARKE, M.D., F.R.S., \\ PHYSICIAN TO THE HOSPITAL FOR DISEASES OF THE NERVOUS SYSTEM, \\ AND \\ WILLIAM R. GOWERS, M.D., \\ assistant physician to UNIVERSITY COLLEge hospital, AND to the \\ NATIONAL HOSPITAL FOR THE PARALYSED AND EPILEPTIC.
}

(Received May 12th-Read May 26th, 1874.)

For an opportunity of seeing the case during life, and of making an examination after death, we are indebted to Mr. Wm. Adams, under whose care the patient was. Mr. Adams has also furnished an account of the early history of the case.

Master W. E-, aged at the time of his death $14 \frac{1}{2}$ years. Both parents are living and in good health. The father, an officer in the army, is a strong healthy man; the mother is a highly nervous hysterical woman. The only other child is a girl, a few years older, and in good health. No history could be obtained of any similar affection in collateral branches. In infancy the boy was well nourished and apparently healthy, but began to walk later than other children-not until he was two and a half or three years old, and then it was in a peculiar way. 
About that time his calves were observed by his mother to be unusually large. As he grew older the peculiarity in his walk became more marked: he carried his body bent slightly forwards and walked with a swinging movement. He was never able to walk far, but when five years old could walk in the manner described about a mile. At this age the calves were noticed to be very large, the thighs were thought to be about the normal size. The arms were fleshy, but were not noticed to be particularly large.

When between five and six years old he became liable to fall in walking, and had great difficulty in getting up again.

A photograph, taken when he was between seven and eight years of age, represents him as a tall, well-nourished, and apparently strongly-built boy, but he was obliged to lean against a pillar for steadiness, and always used a stick in walking on account of his liability to fall. About this time the heels were observed to be somewhat drawn up. As this increased he became unable to walk, and after giving up walking he had some difficulty in straightening the knee-joints, and the elevation of the heels increased.

When nearly nine, in July, 1867, Sir William Fergusson was consulted, and advised division of the Achilles tendons, observing that if the boy could put the heels to the ground he would probably be able to walk. No operation was, however, performed, on account of domestic difficulties.

At the age of $10 \frac{1}{2}$, in January, 1869, he was brought up to London to see Mr. Adams, who, thinking that division of the Achilles tendons would enable the boy to stand and walk, procured him admission into the Royal Orthopædic Hospital. At that time both calves were large and hard, the gastrocnemii being prominent and well defined in outline. The Achilles tendons were also tense and prominent, and the os calcis in each foot elevated so as to produce marked talipes equinus. The hamstring tendons were also tense so as to prevent complete extension of the knee. The thighs were small and the recti feeble. 
He could, however, sit upright very well on a chair, and from this evidence of the state of the spinal muscles it was thought that he would be able to stand and walk upright if the heels could be brought down. The upper extremities were somewhat feeble. The biceps was noted as being particularly small and feeble, offering but slight resistance to passive extension. The pronators and supinators of the forearms were large, hard, and well defined. He could grasp with considerable power. The deltoid on each side was large, prominent, hard, and well defined in outline, and the arm could be held out in an extended position with considerable power. The pectoralis major was decidedly feeble and somewhat atrophied. The trapezius muscle was also somewhat feeble and atrophied, and there was some preternatural mobility about the scapula on each side, probably due in part to a feeble condition of the serratus magnus and latissimus dorai muscles. The difficulty which the boy had in raising himself from the horizontal to the sitting posture was very striking, and appeared to depend, in part at least, on the weakness of the muscles about the shoulder-joint. When accomplished he could very well maintain himself erect in the sitting posture, and no spinal curvature existed.

During his stay in the hospital, from January to July, 1869, both Achilles tendons were divided by Mr. Adams. The hamstring muscles were subjected to forced extension, by which the knee-joints were straightened. The effect was that, with steel supports to the legs, carried up to the hips, he was able to walk about the ward with assistance. He was unable to use crutches on account apparently of the weakness of the muscles about the shoulder-joints ; and with this amount of improvement he returned to the country in July, 1869. Just before leaving town he was seen by Dr. Radcliffe.

Soon after his return home the mechanical supports were unfortunately discontinued, and the boy never stood or walked again. From this time there was a steady loss of voL. LVII. 
power with wasting of muscles both in the upper and lower extremities. The contraction of the knee-joints returned and increased. In 1871 he was quite unable to straighten the knees, and could move only his toes and ankle-joints. The wasting and weakness of the arms increased until he ceased to be able to raise them even to feed himself, and could only put food into his mouth by resting his hand upon his raised and bent knees and lowering his head. The right arm continued stronger than the left.

In the summer of 1872 , being then nearly 14 years of age, he had an attack of gastric fever, which weakened him considerably. Subsequently he suffered from bronchitis, which never completely left him. He was then attended by Drs. Magrath and Workman, of Teignmouth. The general wasting and debility increased, and some difficulty in swallowing came on and continued.

In January, 1873, he was again brought to London to see Mr. Adams, at whose request he was seen by $\mathrm{Dr}$. Radcliffe and by Dr. Richardson. His condition was then noted to be as follows :

Mind quite unaffected. A cheerful clever boy; fond of reading. Voice high-pitched. No apparent weakness of any muscle supplied by cranial nerves. Special senses unimpaired, optic discs normal. No wasting of face; no want of expression in it. Tongue protruded straight and moved freely, unwasted. Complaint was made of slight difficulty in swallowing. The palate appeared to move freely.

Arms.-No power of moving shoulder- or elbow-joints. The wrist-joints could be moved with tolerable freedom, and the fingers well, so that he could write and draw. The elbows -were flexed at nearly a right angle, and could not be straightened. All muscles of the arms were greatly wasted, deltoid, biceps, triceps, and forearm muscles. The wasting, though great, was not extreme. The muscles of the left arm were rather less wasted than those of the right. No fibrillation was seen.

Trunk and back muscles all considerably wasted, though not quite as much so as those of arms. 
Spine presented a moderate degree of lateral curvature, the convexity being to the right.

Legs.-No power over hip- or knee-joints. The ankles could be moved a little, but not much, the calf muscles having again become contracted, and having reproduced the state of talipes equinus which had been removed by tenotomy four years previously. The toes could be moved fairly well. The hip-joints were flexed, the thighs being brought up towards the abdomen, and the knee-joints bent at a right angle : both were rigid from muscular contraction and the rigidity could not be overcome.

All the muscles, both of thighs and legs, appeared much wasted; there was scarcely any prominence of the calves,

Sensibility was everywhere unimpaired. The sphincters were unaffected.

From this date no marked change occurred in his muscular symptoms. His cough became more troublesome and evidence of consolidation in the lungs was found, and his strength rapidly diminished. Towards the end he complained of some increase in the difficulty in

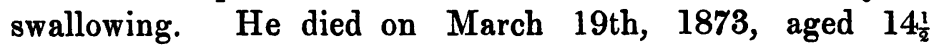
years.

The post-mortem examination, forty hours after death, was made under circumstances of some difficulty.

The wasting and position of the limbs were the same as noted during life.

All the thoracic and abdominal viscera were healthy with the exception of the lungs.' Throughout both lungs were thickly scattered areas of lobular pneumonia, grey in colour, many of them breaking down. Some larger areas of consolidation in the right lung emitted an extremely offensive gangrenous odour. No grey granulations could be seen.

Muscles.-Portions of muscle were removed from the gastrocnemius, the deltoid, and the biceps, on each side.

The gastrocnemius muscles were small, not more than one third of the normal size. Each muscle presented the appearance of a mass of adipose tissue. On section 
it was pale yellow in colour and greasy to the touch. No trace of red tint could be seen in it. Under the microscope it consisted for the most part of distended fatcells, which lay between and separated widely bundles of muscular fibres. The fat-cells were quite similar to those constituting an ordinary lipoma; they varied in size from $\frac{1}{250}$ to the $\frac{1}{1000}$ of an inch. In a few a nucleus could be seen. They contained, when fresh, no crystals. The amount of connective tissue between them was small.

The muscular fibres ran, several together, through the adipose tissue. Some were of normal size, others much less. Their diameters varied from the $\frac{1}{1000}$ to $\frac{1}{3500}$ of an inch. In many places the narrower fibres lay beside the wider ones. Many fibres presented variations in width, being narrower at one place than at another. In some this variation in width was sudden, as at Plate IX, fig. 7. The transverse striation was for the most part, in the narrower as well as in the larger fibres, perfectly distinct. The striæ were, in the larger fibres, about $\frac{1}{1200}$ inch distant from one another, but in some of the smaller they were farther apart. Here and there, in the narrower fibres, the striæ had disappeared, being replaced by granules distributed uniformly through the fibre. In a few of the larger fibres the striæ were assuming a granular aspect. In a few, both large and small, the striæ seemed to be disappearing, fading away, without becoming granular. In no case were any fat-globules seen within the fibres. No distinct division of fibres could be detected. Accompanying the bundles of muscular fibres, changed and unchanged, was a good deal of connective tissue, the fibres of which lay parallel to the muscular fibres. Some of this had the aspect of ordinary fibrous tissue, but much of it contained small oat-shaped nuclei, and had very much the uppearance of empty sheaths of muscular fibres (Plate VII, fig 1.) Indeed in some places it was evidently the case, for on following such fibres for a little distance transverse striation gradually showed itself, at first faint, then more distinct, until the aspect of a distinct fibre was assumed. 
Deltoid.-The deltoid, much below the normal size, had a reddish tint, though considerably paler than natural. The microscopic appearances were similar to those of the gastrocnemius, but less advanced. In places the fibres were separated by a large amount of fat; in other places there was little fat, but much fibrous tissue between them. They presented even greater variation in size than those of the gastrocnemius, being from the $\frac{1}{500}$ to the $\frac{1}{4000}$ inch in diameter. The average size, however, was about $\frac{1}{1000}$ inch. The striæ were farther apart in the narrower than in the larger fibres, the variation being between the $\frac{1}{14000}$ and $\frac{1}{7000}$ inch distance.

The biceps on each side presented naked-eye and microscopic appearances very similar to those of the deltoid, but the amount of fat was less and no fibres were seen more than $\frac{1}{1 \overline{0} 00}$ inch in diameter.

Tendons.-Both Achilles tendons were natural on external appearance, in outline, and thickness.' When divided longitudinally it was evident that $1 \frac{1}{2}$ inch of new tendon had been formed and inserted between the ends of the old tendon, where they had been divided four years previously, the new portion being readily distinguishable from the old by the grey colour and translucency of its tissue as compared with the opaque pearly lustre of the old tendon, and by the absence of the appearance of longitudinal striation which characterised the old. The line of junction, both above and below, was still distinctly traceable, the junction being effected by a process of dovetailing, the grey translucent tissue of the new tendon being inserted between the separated fibres of the old tendon. The naked-eye appearances in this case were precisely similar to those described by Mr. Adams in his work on the 'Reparative Process in Human Tendons.'

Nervous system.- Nothing unusual was found in either the external or internal appearance of the brain and medulla oblongata.

The spinal cord, as it was removed from the body, seemed perfectly healthy and of normal consistence, but 
after being very carefully hardened in a solution of chromic acid, thin sections made in every region revealed, under the microscope, varied and extensive lesions.1 These lesions began, from above downwards, at the level of the second cervical nerves. There was disintegration, in a greater or less degree, of the lateral grey network which is so conspicuous in this region between the caput cornu posterioris and the tractus intermedio-lateralis, and through which the spinal accessory nerve makes its way into that tract. The tract itself was to a certain extent in a state of incipient disintegration, and on one side was, in many sections, traversed by a dilated and congested blood-vessel around which the tissue had begun to suffer. The white columns were not perceptibly altered, but one lateral half of the anterior white commissure was entirely destroyed and replaced by granular débris, by exudations and extravasated blood-globules which also filled the triangular space at the bottom of the anterior median fissure.

On descending through the rest of the cervical region the same kind of morbid changes, to a greater or less extent, were found at different levels, while the anterior and central grey substance on each side was the seat of extensive disintegrations. A similar lesion existed in some of the posterior nerve-roots near their entrance into the caput cornu posterioris, as may be seen in Plate VII, fig 4, at $n$, where the fibres are completely broken up and thus severed from the gelatinous substance, $o$, of the posterior cornu.

Both the lateral and posterior white columns were in many sections much damaged by sclerosis, consisting of a variable degree of disintegration of the myelin or white substance of the longitudinal fibres. The lesions of the grey substance are seen in fig. 1, which represents

1 In order to avoid the error (which is not possible with those observers whose experience in the healthy and morbid anatomy of the cord is great) of mistaking breaches of tissue produced in making sections, for morbid changes, it has been the practice to examine with a powerful lens the cleanly-cut gurface of the cord where the section has been made. 
a transverse section at the upper roots of the sixth cervical nerves. At $a$ is a blood-vessel surrounded by a light area containing granular exudation and partially disintegrated tissue. Similar spaces are seen at $a^{2}, a^{3}, a^{4}$, on the left side, and on the right side several areas of incipient disintegration may be seen in the cervix cornu, $a^{\mathbf{1}}$. But the most striking lesion was in the anterior commissure, $b$, the left half of which was entirely destroyed. Its place on that side was occupied by granular exudation and by extravasated blood-globules, $c$. A little lower down in the cervical enlargement the destruction of these parts was still more extensive. Plate VII, fig. 2, represents the anterior and posterior commissures with the inner portion of each lateral half of the grey substance more highly magnified than fig. 1. The anterior commissure, $b$, extends very little beyond the median line, on the left side, the rest being completely destroyed. In front of it is a mass of granular exudation, $d$, and a blood-vessel, $e$, entering at the anterior median fissure, $f$, extends into a large area of disintegration, $g$, at the inner portion of the lateral grey substance, the vessel itself sharing in the destruction. At $h h$, just where the anterior commissure winds round the inner side of the anterior cornu, there are two considerable tracts of disintegrated tissue. In some sections of the cervical enlargement the posterior commissure was also a little damaged, while in others both commissures were uninjured. In the triangular space at the bottom of the anterior median fissure a considerable extravasation of blood was very common. In the base of the posterior cornu on the right side, at the point $p$, in Plate VII, fig. 1 , there was a remarkable area of disintegration surrounding a tubular cavity (see Plate VII, fig. 3). At the outer border of this area, $q q q q$, the grey substance was easily seen to be in process of disintegration, and farther in, this process had gone on to the formation of a pellucid and coagulable fluid surrounding a cylindrical tube, $r$, which was lined by an extremely thin layer of granules.

In the upper portion of the dorsal region the morbid 
changes were less frequent and extensive, but here and there the anterior white commissure was partially destroyed. In the middle and lower portions - of this region, however, the lesions were greater than in any other place. The lateral grey substance on the outer sides of the posterior vesicular columns, including the tractus intermedio-lateralis, was severely damaged by disintegration, while the anterior white commissure was in many sections wholly or partially destroyed. At the lowest part of this region and the commencement of the lumbar enlargement the lesions were most extensive and striking. Plate VII, fig. 5, represents a transverse section of the grey substance in this locality. The central and lateral parts on each side, $i i$, were severely damaged by softening and disintegration, presenting the appearance of a piece of cloth irregularly worn into holes. To the naked eye there appeared to be a cavity on each side occupying the central part of the grey substance.

These large areas of lesion, however, were still traversed by many fibres whose course is almost entirely peculiar to this particular portion of the cord. One set of these fibres is derived from the posterior roots of the nerves, as seen at $j$, and curves forwards and inwards to a point, $k$, in front of the posterior vesicular column, $l$. Other sets of fibres proceed from the anterior part of the lateral column and from the tractus intermedio-lateralis, and also from the posterior transverse commissure, and run transversely inwards and outwards to the same point, $k$, where both sets become longitudinal in their course along the grey substance. ${ }^{1}$ As in the cervical region, the anterior commissure was often greatly damaged, and in some sections, as shown in Plate VIII, fig. 6, only the central portion, $b$, remained, its lateral portions, with some of the contiguous grey substance, having been almost entirely destroyed.

1 The course of these fibres, the functions of which must be of great importance, has not been hitherto described by any anatomist. An account of them, and of their relations to surrounding parts, will shortly be communicated to the Royal Society.-J. L. C. 
In the middle and lower parts of the lumbar enlargement the lesions were less serious. The grey substance was only'slightly affected here and there by small patches of incipient disintegration, and the anterior commissure was much less damaged than in the other regions of the cord; but some of the nerve-cells were evidently wasted to a certain degree; their processes were shrunk, and their angles were more obtuse than natural. The anterior roots of the nerves were in many places injured by streaks of disintegration of variable size, and in some sections the fibres at their origin, as well as the border of the anterior horn from which they sprang, were completely destroyed, as shown at $m \dot{m}$, Plate VII, fig 5, where the myelin or white substance of the fibres is stripped from their axes-cylinders and appears in the form of globules.

In the lower portion of the lumbar enlargement and in the conus medullaris the lesions of the grey substance were severer and more extensive. The central part of the anterior cornu and the outer part of the cervix cornu posterioris were very much damaged by continuous disintegration. In some of the sections at the level of the upper sacral nerves scarcely any large nerve-cells could be seen in the anterior cornu. Some of the nerve-cells were likewise atrophied, and contained more pigment than natural. ${ }^{1}$

Of the identity of the disease in this case with that described by Duchenne under the name of "pseudohypertrophic paralysis," there can, we think, be no question, although at the time of death the muscles were all smaller and not larger than the normal. At an earlier period the muscles of the calf had presented a decided increase in bulk, and this, together with the naked-eye and micro-

1 It may be well to state that a piece of spinal cord about an inch long was taken from a patient of $\mathrm{Mr}$. Adams about three years back, and sent to me for examination, but it had been so-rapidly hardened in strong solution of chromic acid that it was impossible to make sections on account of its friability. In partial sections, however, I discovered unmistakable areas of transparent granular disintegration. The case was a typical example of pseudo-hypertrophic muscular paralysis.-J. L. C. 
scopic appearance of their substance, the enormous accumulation of fat between the bundles of muscular fibres, sufficiently characterises the case as an instance of that disease.

It further agrees with most of the recorded cases in sex (four out of five being males), in the age at which the symptoms commenced, and in the early and chief affection of the gastrocnemii and solei muscles.

A condition of atrophy in other than the calf muscles is not unfrequent in this affection. Out of 81 cases collected by Friedreich some muscles were atrophied in 37 ; most frequently the pectoral muscles, next in frequency the muscles of the shoulder, back, and upper arm; least frequently those of the thigh, forearm, and hand. We believe that in no case bitherto recorded has there been atrophy of the muscles of the calves, previously increased in size.

In several of the cases on record, especially, for instance, in that described by Cohnheim, the identity of structural change in the muscles enlarged and in those atrophied was clear, and its characters corresponded in almost every particular to those presented by this case.

In the two post-mortem examinations made some years ago by Dr. Meryon, and in the more recent examinations by Cohnheim and Charcot, no structural change in the spinal cord was discovered. Mr. Kesteven has described, in a case of imbecility associated with this disease, dilatation of the perivascular canals and spots of granular degenetion, but none of the latter exceeded in size $\frac{1}{50}$ th of an inch, and they are described as being in the cord "few and far between." Certain pathological appearances were found by Barth $^{1}$ in the cord of a man who died, aged 44, having presented for three years the symptoms of this disease, enlargement of some and atrophy of other muscles, the microscopic structure of both being characteristic of this affection. The changes consisted of " partial degeneration of the antero-lateral columns, due to proliferation of the neuroglia and the replacement of nerve-tubes by a

1 'Archiv der Heilkunde,' xii, 1871, p. 126. 
finely granular and very vascular substance containing corpora amylacea. The ganglion-cells of the anterior horns were diminished in number throughout the cord. Corpora amylacea also lay between the fibres of the anterior roots of the nerves, the posterior roots being normal. Both anterior and posterior roots were surrounded by much adipose tissue, which filled also the intervertebral foramina and the interior of the vertebral canal."

From this case that which we have recorded above differed in the absence of any increase in the adipose tissue outside the cord and in the chief and considerable affection of the grey matter. 


\section{DESCRIPTION OF PLATES VII, VIII, \& IX.}

\section{Microscopical apprarances of Spinal Cord and Musches in a Case op Pseddo-hyphrtrophic Muscular Paralysis.}

\section{Plate VII.}

Fra. 1.-Transverse section of grey substance of spinal cord at lower part of fifth cervical nerves. $\times 10$.

FiG. 2.-Commissural portion, a few sections lower down. $\quad \times 25$.

FrG. 3.-Area of disintegration, inner part of lateral grey substance, lower cervical region. $\times 35$.

Fia. 4.-Extremity of posterior cornu, with the corresponding posterior root interrupted by disintegration. $\times 200$.

FIG. 5.-Anterior root, lumbar region, interrupted by disintegration.

\section{Puate VIII.}

FiG. 6.-Transverse section of grey substance at the highest part of the lumbar enlargement.

\section{Puate IX.}

FIG. 7.-Portion of gastrocnemius muscle, showing the narrowed muscular fibres, connective tissue, and nuclei between the adipose tissue. $\times 200$.

FrG. 8. -From the same muscle, healthy-looking fibres, accompanied by increased quantity of connective tissue.

\section{Explanation of Letrers.}

$a^{1}, a^{2}, a^{3}, a^{4}$. Areas of disintegration in the grey substance of the spinal cord. Fig. 1.

b. Anterior commissure.

c. Extravasated blood-globules.

d. Granular exudation. Fig. 2.

e. Blood-vessel.

$f$. Anterior fissure.

$g$. Large area of disintegration.

$h$. Do., less advanced.

$i$. Lateral portions of grey substance. Fig. 6.

$j$. Some of posterior roots of nerves.

$k$. Point where thin fibres become longitudinal.

$l$. Posterior vesicular column.

$m, m^{1}$. Extensive disintegration at origin of roots of anterior nerves. Fig. 5 .

$n$. Disintegration of a large posterior at its entrance into the point of posterior horn.

o. Point of posterior horn.

$q$. Remarkable area of disintegration surrounding a tubular cavity, $r$, at the base of posterior horn. Fig. 3. 


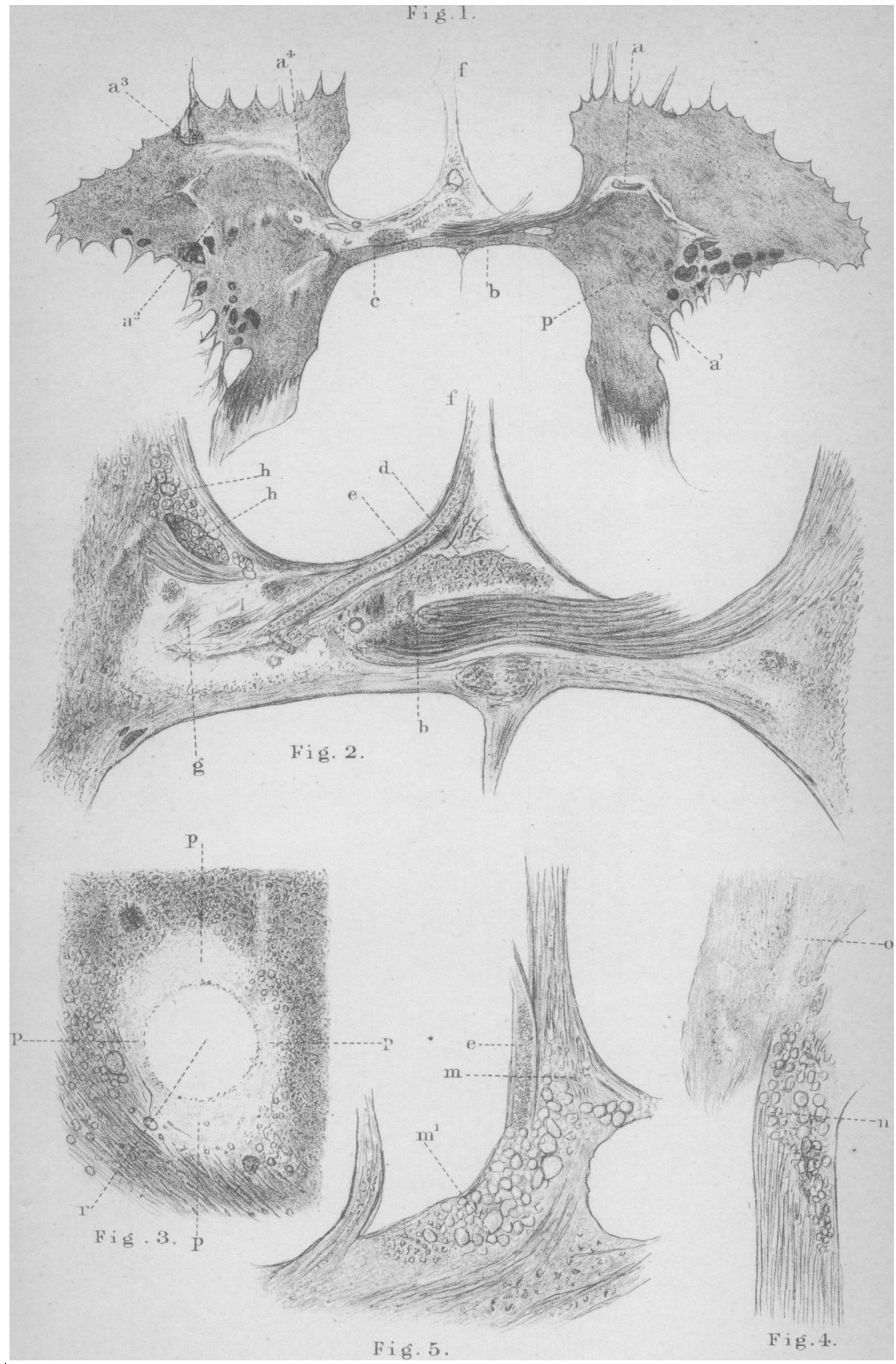




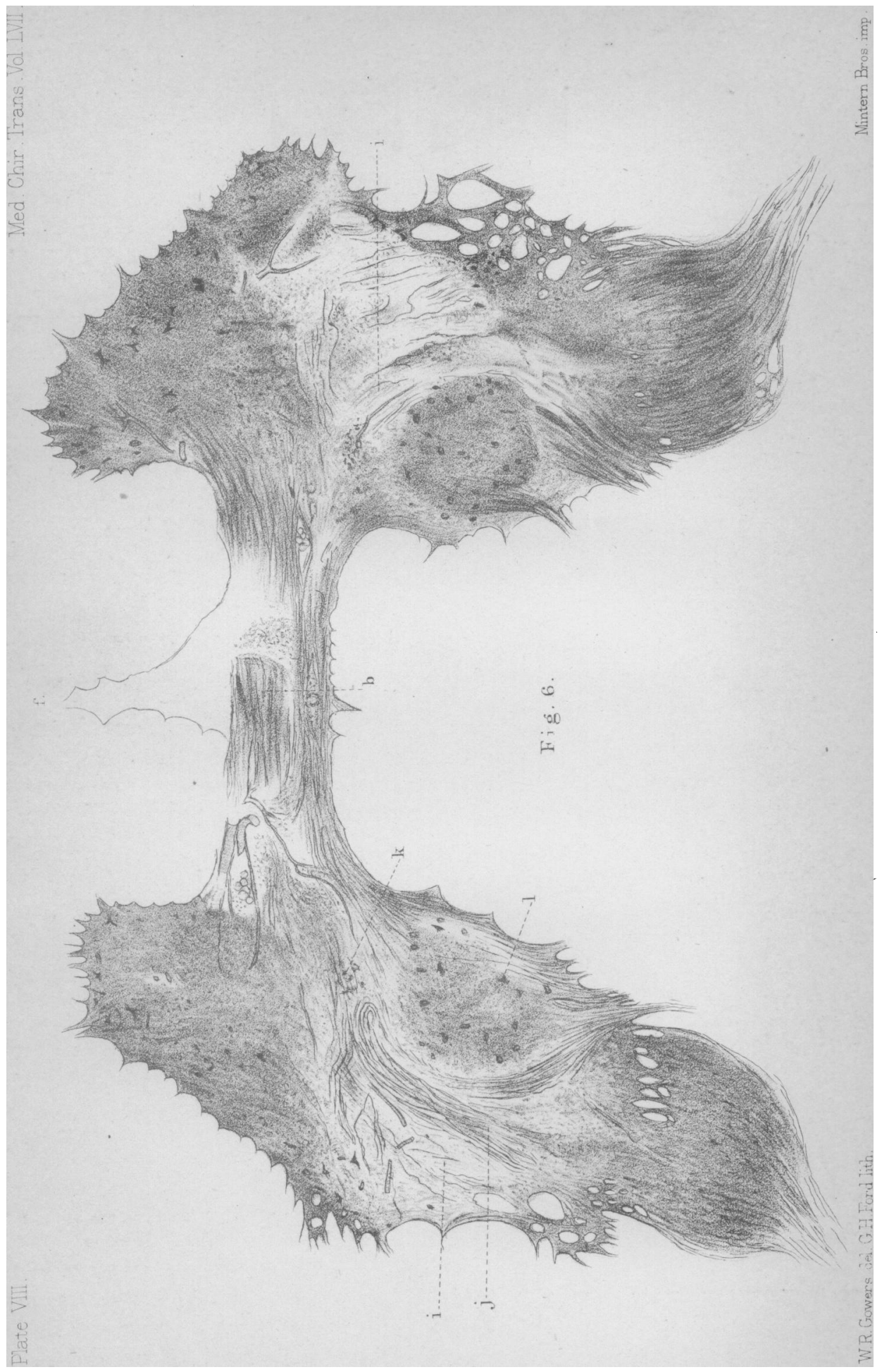



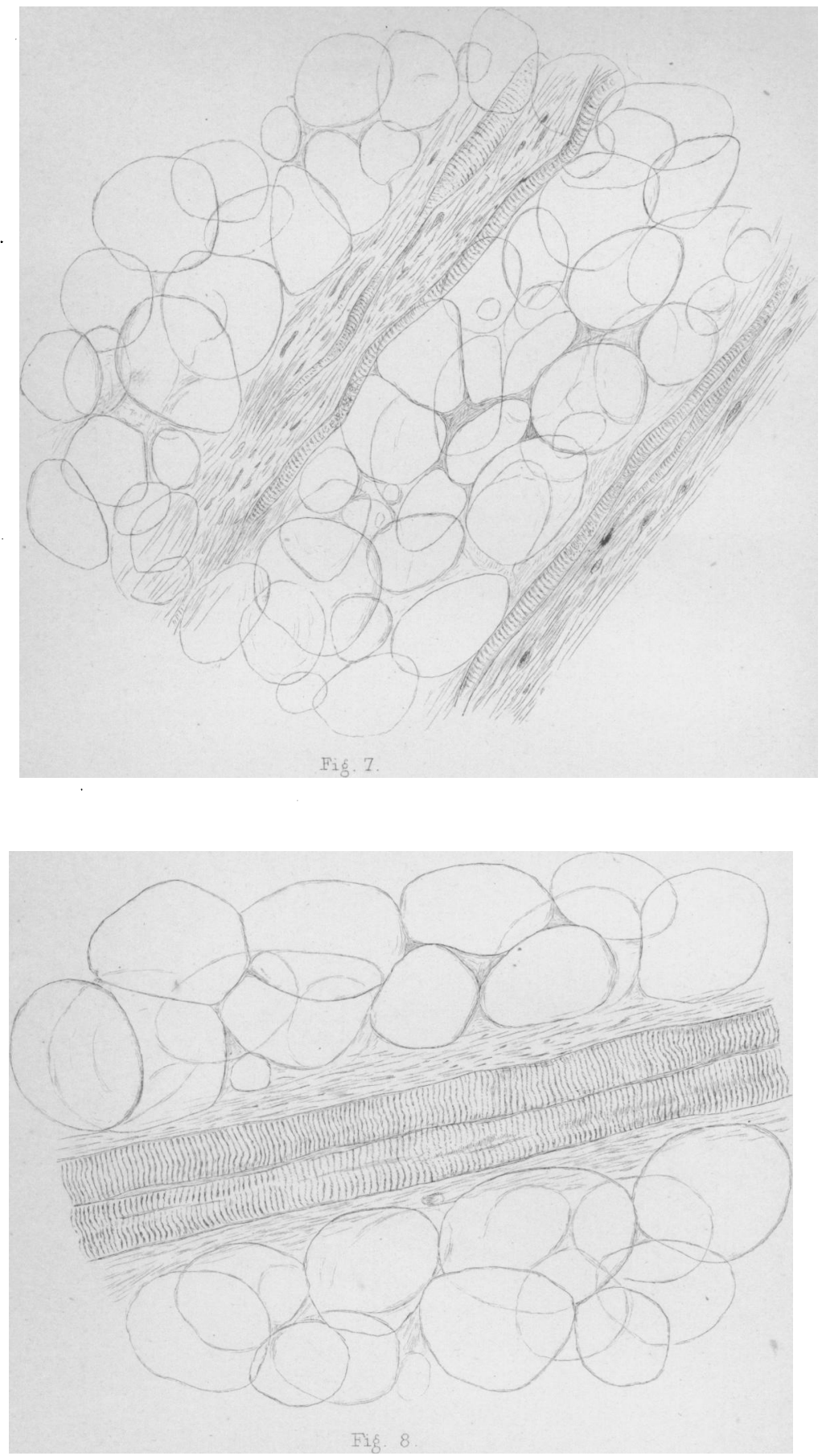